Article

\title{
Exploring Public Support for Large-Scale Commercial Axis Deer Harvests in Maui, Hawaii
}

\author{
Elena C. Rubino ${ }^{1,2,3, * \mathbb{D}}$ and Christopher K. Williams ${ }^{1,4} \mathbb{D}$ \\ 1 Joseph R. Biden School of Public Policy and Administration, University of Delaware, 184 Academy Street, \\ Graham Hall, Newark, DE 19716, USA; ckwillia@udel.edu \\ 2 Division of Agriculture, Arkansas Forest Resources Center, University of Arkansas System, Monticello, \\ AR 71656, USA \\ 3 College of Forestry, Agriculture, and Natural Resources, University of Arkansas at Monticello, \\ 110 University Court, Monticello, AR 71656, USA \\ 4 Department of Entomology and Wildlife Ecology, University of Delaware, 531 South College Ave, \\ 250 Townsend Hall, Newark, DE 19716, USA \\ * Correspondence: rubino@uamont.edu
}

check for updates

Citation: Rubino, E.C.; Williams, C.K. Exploring Public Support for Large-Scale Commercial Axis Deer Harvests in Maui, Hawaii. Sustainability 2022, 14, 1837. https://doi.org/10.3390/ su14031837

Academic Editor: Cheryl Lohr

Received: 15 January 2022

Accepted: 2 February 2022

Published: 5 February 2022

Publisher's Note: MDPI stays neutral with regard to jurisdictional claims in published maps and institutional affiliations.

Copyright: (C) 2022 by the authors. Licensee MDPI, Basel, Switzerland. This article is an open access article distributed under the terms and conditions of the Creative Commons Attribution (CC BY) license (https:// creativecommons.org/licenses/by/ $4.0 /)$.

\begin{abstract}
Commercial harvests have been effectively employed to manage wildlife populations across the world. Although commercial harvesting of the nonnative, invasive axis deer (Axis axis) in Maui, Hawaii, occurs at small scales and only on private lands, there is potential for large-scale implementation to be used as a population management tool. To investigate local stakeholder interest in a hypothetical, large-scale commercial harvest of axis deer, we used an online survey of individuals and businesses in Maui to analyze their attitudes towards axis deer populations and management, their experiences with axis deer, and potential to utilize axis deer venison and products, as relevant. We found evidence of public support for commercial harvesting to be employed as one of the many tools available to manage axis deer populations. Additionally, we documented support on both the supply-side and demand-side for axis deer-derived products that may be available if large-scale commercialized harvesting were implemented. We leverage these results to contribute to conversations about commercial wildlife harvesting in the United States by challenging assumptions that the practice is inconsistent with the public's perceptions of the North American Model of Wildlife Conservation and suggesting policies and programs that would ease axis deer commercial harvest growing pains.
\end{abstract}

Keywords: Axis axis; cervid; commercial harvest; invasive species; population management

\section{Introduction}

Recreational hunting is recognized as a useful wildlife management tool contributing to livelihoods, culture, and leisure [1]. Cervid species throughout Europe and North America, in particular, have increased to the extent that recreational hunting is considered vital to achieving population management goals [1]. However, there is also acknowledgment that, in many contexts, recreational hunting alone is not enough to reduce overabundant wildlife populations. For example, Blossey et al. [2] found that recreational hunting was not sufficient to reduce white-tailed deer (Odocoileus virginianus) populations in central New York State, USA, nor their browse rates and associated ecological impacts (e.g., seedling depredation). This is particularly true of nonnative, invasive species that benefit from life-history characteristics that allow them to thrive in new habitats (e.g., rapid growth, high fecundity, high tolerance of a range of habitat conditions, and a lack of natural predators [3]). In these instances, recreational hunting opportunities are not adequate to control invasive species populations [4].

A variety of wildlife population control methods are used in attempts to manage overabundant population numbers (e.g., sterilization, trap and transfer, culling/ 
sharpshooting [2,5,6]), yet each requires financial resources that are not always available [3], unlike recreational hunting. As such, wildlife managers have explored and implemented commercial harvests as another management tool, where allowing hunters to profit from the sale of harvested wildlife creates a financial incentive for hunters to harvest beyond their personal thresholds [6]. Globally, commercial harvests have been effectively implemented to manage native wildlife populations, such as urban western gray kangaroo (Macropus fuliginosus) populations in southwestern Australia [7], and nonnative wildlife populations, such as red deer (Cervus alaphus) in New Zealand [8].

Similarly, the strategy has been utilized to attempt to control various nonnative, invasive fish species (e.g., black carp (Mylopharyngodon piceus), bighead carp (Hypophthalmichthys nobilis), and silver carp (H. molitrix Valenciennes)) in the United States [3]. Although commercial harvests of white-tailed deer have been discussed [2,6], the United States has yet to see the commercial harvest of any native mammals due to its perceived incompatibility with the North American Model of Wildlife Conservation (NAMWC) and associated regulations [6]. However, the commercial harvest of nonnative invasive species has the potential to operate outside of the fundamentals of the NAMWC.

Axis deer (Axis axis) are native to India, Nepal, Bhutan, Bangladesh, Sri Lanka, and Pakistan, where large carnivores regulate populations. In 1867, eight axis deer were introduced to the Hawaiian island of Molokai as a gift to King Kamehameha V, and without natural predators, competition, or mortality-affecting diseases/parasites [9], the population increased to nearly 7000 within 30 years [10]. Small populations were transported to other Hawaiian islands, including Maui in 1959, for the purpose of providing hunting game, and populations exploded in many of these instances, as well. Today, an estimated 50,000 deer inhabit Maui alone [11], and the deer have caused ecological and socioeconomic damage throughout the island, including the degradation of native ecosystems (due to a lack of coevolution with cervid species), over USD 1 million in damage to crops, golf courses, and ornamental gardens [9], and deer-vehicle collisions [11]. Despite their high cultural, economic, aesthetic, and recreational values as recognized by local residents and hunters in Maui and across the islands [11,12], the damage axis deer cause has prompted the governor's " 30 by 30 " plan to fence $30 \%$ of the state's priority watersheds by 2030 in an attempt to protect them from axis deer [11]. However, criticisms of the plan highlight problems with fencing in general; fencing can be prohibitively expensive, it is not always effective in keeping persistent deer out, and merely excludes deer from areas rather than reducing populations [11].

To encourage population control via recreational hunting, Hawaii's Department of Forestry does not restrict axis deer hunting on public lands with bag limits or seasons [9]. Further, commercial harvesting of the nonnative axis deer in Hawaii is permitted on private lands when conducted in accordance with stringent United States Department of Agriculture (USDA) oversight for food safety; but it is not legal on public lands and is currently only conducted at very small scales due to these regulations [11]. Although axis deer commercial harvesting is in its infancy, it represents a significant opportunity for population control if it is allowed to mature in scale.

A key component of exploring the large-scale viability of commercial harvesting as a population management strategy for axis deer (or other mammals) in the United States is understanding stakeholder support. Indeed, wildlife management agencies rely on surveys of stakeholders to measure preferences towards and support for population management alternatives, particularly as they relate to cervid [13] and nonnative, invasive [14] species management. However, as Lohr et al. [12] note, human dimensions research for Hawaii's terrestrial species is limited, and studies documenting stakeholder support for axis deer management alternatives are lacking. The purpose of this research was to help fill this gap and to serve as an exploratory study to investigate local stakeholder preferences for management alternatives, specifically focusing on interest in a hypothetical, large-scale commercial harvest and its subsequent axis deer-derived products. To achieve this aim, we surveyed individuals and businesses in Maui (island) and analyzed their attitudes towards 
axis deer populations and management, their experiences with axis deer, and the potential to utilize axis deer venison and products, as relevant. Our goal was to use these results to provide evidence of the level of local support for commercial harvests as a population control strategy and contribute to conversations about commercial wildlife harvesting in the United States by challenging assumptions that the practice is inconsistent with the public's perceptions of the NAMWC and suggesting policies and programs that would ease commercial harvest growing pains.

\section{Methods}

We developed two different survey instruments for this study, both of which received IRB approval (University of Delaware Human Subjects Approval \# 544885-1) and resulted in data analyzed using StataBE 17 statistical software. The first instrument was designed to explore the perceptions of individuals who lived or hunted in Maui related to axis deer populations and management. The instrument included attitudinal questions about population growth and its effects on people and the environment, questions measuring preferences towards population management alternatives (e.g., fencing, trap and transfer; each of which included a brief description of the alternative), questions about perceptions of large-scale commercial harvesting as a population control strategy, and demographic questions. To reduce the length of the survey for any given respondent, respondents who indicated that they had purchased a Hawaiian hunting license within the past two years were asked about their willingness to participate in a hypothetical commercial axis deer harvest. Those who had not purchased a Hawaiian hunting license within the past two years were asked about their willingness to potentially purchase axis deer-derived goods.

We administered the survey online using Qualtrics survey software and we collected data from January through March 2014 using a combination of systematic random sample and convenience sample approaches [15], which involved dissemination over a variety of channels. First, we used the Maui Yellowbook "Business and Resident: 2014-2015" section to generate a random selection of 1000 residents. Approximately five residents per page were selected by selecting every tenth resident listed. If the tenth entry was a business, the next residential entry listed was selected. We mailed a one-page, push-toweb letter [16] to each address, which included information explaining the background and purpose of the survey and a shortened web link to the survey. Additionally, web links to the survey were published in articles in The Maui News and Maui Now local newspapers, as well as shared on the latter's Facebook page. Finally, to increase the likelihood of reaching hunter respondents, we shared the survey information and web link on multiple Maui hunting group online bulletin boards and with various hunting groups and axis deer hunting guides so they could forward it to their membership and clients. Each channel used to distribute the survey provided potential respondents with the same information regarding the purpose of the survey and research, how to complete the survey, and informed consent information.

The second instrument was designed to investigate local Maui businesses' interests in offering axis deer venison and other products that would be available should large-scale commercial harvesting be adopted as a population control strategy. Using extensive Google searches, we generated a sampling frame of locally owned and operated businesses that might be impacted by such a large-scale commercial harvest based on the products or the services the business offered. Specifically, we searched for local hunting guides, businesses in the food industry (e.g., restaurants, chefs, grocery stores, delis, meat suppliers), pet food companies, zoos/animal sanctuaries, businesses in the jewelry industry (e.g., jewelers, bead sellers/manufacturers), and leather smiths/tanners. Using the Google searches and follow-up phone calls to businesses, we generated a list of 133 viable email addresses of businesses that fit into one or more of these categories. Given the small available sampling frame, we attempted a census [15] by emailing each address with information about the study, the purpose of the research, and the link to the survey. We programmed logic into 
the instrument to ensure that only relevant questions were displayed based on the type of business participating in the survey. The initial email and four reminder emails were sent from September through December 2013.

\section{Results}

\subsection{Individual Survey}

A total of 180 respondents completed at least $75 \%$ of the survey and were included in data analysis. Approximately 56\% of respondents were male and ages ranged from 18 to 79 , with an average age of 52 years old $(S D=13.77)$. Most respondents $(93.10 \%)$ indicated they primarily resided in Maui, whereas 3.45\% lived in another Hawaiian island and the remainder lived in another US state or country. Over half of respondents $(59.30 \%)$ had a bachelor's or graduate degree, $16.28 \%$ had an associate's degree, and $23.26 \%$ had a high school degree or equivalent. The majority of respondents (71.11\%) owned land in Maui, with most of these respondents (83.59\%) owning $<1.2$ ha (3 ac), 11.72\% owning $1.2-4.1$ ha (3-10 ac), and $4.69 \%$ owning $>4.1$ ha (10 ac).

Approximately $65 \%$ of respondents believed that there were a lot more deer in Maui as compared to the previous five years. An additional $17.22 \%$ of respondents believed there were a few more deer, $7.78 \%$ believed populations were about the same, $3.89 \%$ believed there were either a few less or a lot less, and $6.67 \%$ were unsure. Along with a perception of the increased axis deer population, there also was an accompanying perception of damage. A total of $29.13 \%$ of landowners had experienced damage from axis deer on their property, where $19.69 \%$ of landowners had experienced landscaping/yard damage, $13.39 \%$ experienced agricultural damage, $11.02 \%$ experienced damage to personal gardens, $3.15 \%$ had fencing damaged, and $1.57 \%$ experienced competition for forage in their cattle pastures.

In response to the perceptions of increased populations and damage, $42.22 \%$ of respondents indicated the axis deer population should be greatly decreased, $32.22 \%$ believed the population should be decreased, and $20.00 \%$ believe it should stay the same. Of note, no respondents indicated axis deer populations should be greatly increased, $2.78 \%$ believed they should increase, and $2.78 \%$ were unsure. Recreational hunting was the most supported management alternative, on average, with commercial harvesting and fencing also garnering support (Table 1). On average, respondents were neutral regarding support for the remaining alternatives, although the prospect of not taking any management action was not supported. We then specifically asked about concerns regarding the potential for large-scale commercial axis deer harvesting as a population management strategy and $34.27 \%$ did not foresee any problems, $42.70 \%$ foresaw few and/or minor problems, $18.54 \%$ of respondents indicated they foresaw many and/or serious problems with this strategy, and $4.49 \%$ were unsure.

Of the 45 respondents who indicated they had purchased a Hawaiian hunting license within the past two years, $71.11 \%$ only or primarily hunted axis deer, $17.78 \%$ occasionally hunted axis deer but mostly hunted other species, and $11.11 \%$ had never hunted axis deer. Greater than a third of respondents who had hunted axis deer (37.50\%) spent over 100 days within the past two years hunting axis deer. Approximately $23 \%$ had hunted between one and 39 days within the past two years, $20.00 \%$ had spent 40 to 99 days, and $20.00 \%$ were unsure. Nearly half (46.15\%) of hunter respondents indicated they would be interested in participating in a commercial axis deer harvest, 38.46\% indicated they might be interested, and $15.38 \%$ were not interested. More than half of hunter respondents indicated their hunting behavior would change if they could sell axis deer meat they had harvested, with $27.50 \%$ indicating they would hunt much more often and $25.00 \%$ indicating they would hunt a little more often. Nearly a third (32.50\%) indicated their behavior would not change, whereas $5.00 \%$ said they would hunt much less and $10.00 \%$ were unsure. Approximately $35 \%$ of hunter respondents strongly agreed or agreed they would benefit from being able to sell harvest axis deer meat, whereas $32.50 \%$ neither agreed nor disagreed, $5.00 \%$ disagreed or strongly disagreed, and $10.00 \%$ were unsure. 
Table 1. Support for management actions of axis deer among respondents of the individual survey, in Maui Island, Hawaii, USA, 2014.

\begin{tabular}{|c|c|c|c|c|c|c|c|}
\hline & \multirow[b]{2}{*}{ Mean } & \multicolumn{6}{|c|}{ Percentage of Response (\%) } \\
\hline & & $\begin{array}{l}\text { Completely Support } \\
\text { (1) }\end{array}$ & (2) & $\begin{array}{l}\text { Neutral } \\
\text { (3) }\end{array}$ & (4) & $\begin{array}{l}\text { Do Not Support at All } \\
\text { (5) }\end{array}$ & $n$ \\
\hline Recreational hunting & 1.59 & 76.00 & 8.57 & 4.57 & 2.29 & 8.57 & 175 \\
\hline Commercial harvesting & 2.10 & 54.29 & 16.00 & 9.14 & 6.29 & 14.29 & 175 \\
\hline Fencing & 2.13 & 51.15 & 13.22 & 17.82 & 7.47 & 10.34 & 174 \\
\hline Hired sharpshooting & 2.84 & 34.69 & 10.98 & 16.76 & 10.40 & 27.17 & 173 \\
\hline Contraceptives & 2.96 & 34.88 & 5.23 & 20.35 & 8.14 & 31.40 & 172 \\
\hline Trap and transfer & 3.10 & 32.56 & 7.56 & 13.95 & 9.30 & 36.63 & 172 \\
\hline Take no management action & 4.26 & 7.74 & 4.17 & 11.90 & 6.55 & 69.64 & 168 \\
\hline
\end{tabular}

Of the 128 non-hunter respondents, $71.88 \%$ indicated they would be interested in purchasing axis deer meat at the store and/or as a dish in a restaurant. Similarly, $68.63 \%$ of non-hunter respondents who owned pets $(n=102)$ were interested in purchasing pet food or treats (e.g., axis deer bones, antlers, or hooves as chew toys) made from axis deer meat/parts. Approximately $47 \%$ of non-hunter respondents who wore jewelry $(n=86)$ were interested in purchasing jewelry made from axis deer antler beads.

\subsection{Business Survey}

Of the 133 businesses in our sampling frame, 22 completed the survey (Table 2), representing a response rate of $16.54 \%$. Four hunting guides responded, two of whom served as part-time hunting guides mostly for novice bowhunters and two of whom worked as guides as their main source of income. All four guides noted that they did not believe current customers' behaviors would change if hunters could sell the axis deer meat they harvested; however, two indicated that they might see a small increase in new customers (i.e., hunters who had never hunted with a guide before), whereas the other two did not believe they would see any change in new customers. When asked about concerns regarding the potential for large-scale commercial axis deer harvesting as a population management strategy, two did not foresee any problems. One guide foresaw a few and/or minor problems, citing access to deer herds as a potential issue, and another guide foresaw many and/or serious problems, noting that "illegal poaching and liability would heavily increase on private land, which would be a safety issue". Similarly, when asked about their (dis)agreement regarding if businesses would benefit from customers being able to sell their harvested venison, one strongly agreed they would benefit, one agreed, one neither agreed nor disagreed, and one disagreed, citing the potential for poaching as a problem.

Table 2. Survey responses from businesses in Maui Island, Hawaii, USA, 2013.

\begin{tabular}{lll}
\hline & Number Contacted & Number Responded \\
\hline Hunting guide & 6 & 4 \\
\hline Restaurant/catering industry & 19 & 9 \\
\hline Grocery store/deli & 39 & 1 \\
\hline Meat supplier & 5 & 2 \\
\hline Zoo/animal sanctuary & 2 & 1 \\
\hline Pet food company & 11 & 2 \\
\hline Jewelry industry & 50 & 3 \\
\hline Leather smith/tanner & 1 & 0 \\
\hline Total & 133 & 22 \\
\hline
\end{tabular}


Nine respondents categorized themselves as some combination of a restaurant, café, catering business, and/or personal chef. All of these respondents answered that they cater to customers preferring local and organic products and none of these respondents currently offer venison products or dishes. All but one respondent indicated they would be interested in offering axis deer venison products or dishes, where the exception was a vegan restaurant. Of those interested in offering axis deer venison, five indicated this was due to the added benefit of helping to control deer populations and three indicated this was unrelated to the overpopulation problem.

One grocery store responded to the survey, indicating they cater to customers who prefer to buy local and organic products. Although the store did not sell venison at present, the respondent answered they would be interested in selling ground axis deer venison in the future, particularly due to the added benefit of helping to control deer populations. Two businesses described themselves as meat suppliers, where only one indicated they cater to customers preferring local and organic products. One supplier noted they would be interested in buying axis deer venison because they carried farmed New Zealand venison, although it was not a top-selling item. This respondent was interested in axis deer venison because "a local, wild product would have a lot more customer interest". The other meat supplier indicated they were not interested in supplying axis deer venison due to a perceived lack of demand.

Two pet food companies responded, both indicating they cater to pet owners looking for organic and local pet food. They both noted an interest in buying axis deer meat or parts for their food/treats. One respondent was interested in buying axis deer meat, meaty bones, bones stripped of meat, antlers, hooves, livers, and hearts, whereas the other stated they would have to explore which deer parts were marketable but was not interested in including axis deer bones stripped of meat or antlers in their product line. Similarly, the one respondent from a zoo/animal sanctuary indicated they currently purchase beef and chicken for their five carnivorous bird species, but would only potentially be interested in purchasing axis deer meat for their tiger "if the price were substantially cheaper than beef or chicken and if the meat was inspected". The respondent indicated the zoo was not interested in buying carcasses, meaty bones, bones, antlers, hooves, or other axis deer parts.

Two jewelry makers responded to the survey, both of whom stated their customers are predominantly from US states other than Hawaii. One indicated that, although they do not often use beads in their jewelry, they would be interested in using axis deer antler beads because cattle bone beads carved in traditional Polynesian designs tend to be very popular. This respondent was also interested in selling packages of pre-made axis deer antler beads. The other jewelry maker respondent was not interested in making jewelry from axis deer antler beads nor selling packages of beads due to a perceived lack of demand. One bead seller/manufacturer responded indicated they would be interested in selling packages of pre-made axis deer antler beads but did not have the equipment to create beads if given axis deer antlers.

\section{Discussion}

Our findings provide two key takeaways regarding the potential to use large-scale commercial axis deer harvesting as a population management strategy. First, we provide evidence that there is public support for commercial harvesting to be employed as one of the many tools available to manage axis deer populations. Our results mimicked patterns found in public perceptions of white-tailed deer population control studies, where recreational hunting is the most preferred management alternative, but additional alternatives (e.g., sharpshooting) are often supported when recreational hunting alone cannot achieve population goals $[17,18]$. In fact, our study found that commercial harvesting was more supported than hired sharpshooting in this context. Second, we documented support on both the supply-side and demand-side for axis deer-derived products that may be available if large-scale commercialized harvesting were implemented. As VerCauteren et al. [6] note, commercial harvests are only feasible if there is a demand for markets to exist for deer 
products. Notably, recent research has linked novice hunter interest in obtaining local food and game meat to the growing "locavore" movement [19], and our study offers an initial indication that Maui consumers may share this interest in local organic meat and products. Due to the exploratory nature and age of this research and associated methodology, we recognize that these results are not necessarily representative of the populations discussed, although axis deer populations have continued to increase in the time between the survey was conducted and present. The small sample size and response biases, particularly from the convenience sample, may limit the generalizability of our survey findings [15], but we contend that the data collected achieves the purpose of this study in serving as an exploration of previously unstudied local stakeholder preferences and attitudes.

More generally, this study contributes to the limited literature regarding commercial harvest as a wildlife population control strategy, particularly in a United States setting. Although the NAMWC expressly prohibits commercial markets for game as a direct reaction to the unsustainable harvest and decimation of wildlife populations due to market hunting, there have been arguments that the NAMWC paradigm must be amended to account for new realities $[6,20]$. Furthermore, there is also a recognition that the NAMWC has always allowed for exceptions, including exceptions of the elimination of commercial markets for wildlife, as fur markets, commercial fisheries, and captive cervid breeding all exist today within the NAMWC [20].

We argue that developing the necessary policies and programs to feasibly implement a large-scale commercial harvest of axis deer in Maui would be an ideal case to pilot commercial harvesting for cervid population control in the United States as the jurisdiction is geographically contained and public support for population control is likely greater for such an invasive, nonnative species, as compared to native species. Currently, food safety regulations and associated logistics are the greatest hurdles to a large-scale commercial harvest. The few, small-scale commercial harvest operations in Maui must report straight to the USDA as Hawaii does not have a meat inspection service [11]. Thus, for each harvest, a USDA inspector must accompany the harvester and examine each deer prior to harvest. Successful harvesting can only involve a single shot to the skull, rendering the deer immediately unconscious [11]. Furthermore, the lack of state resources available to inspect and approve game meat processors means that the harvester must bear the burden of providing processing as well [11].

Hawaii must allow for creative solutions to these regulatory issues while still ensuring food safety. As VerCauteren et al. [6] suggest, proof of proficiency and training in harvest techniques and proper handling of meat in the field could be provided by all who aim to participate in commercial harvesting as a way to avoid the cost of hiring a USDA inspector each harvest. A plan of work with a private meat-processing facility with proper food safety oversight would also be necessary [6], or Hawaii could modify the strategy employed by other states that have successfully developed public-private partnerships between deer processors and recreational hunters seeking to donate their venison [11]. Alternatively, a small fleet of mobile game abattoirs could be funded by the state and made available for rent. These mobile game meat abattoirs are gaining popularity in South Africa as an effective way to safely process game meat in the field during excess game culling operations on private wildlife ranches [21]. By allowing for innovative approaches to comply with food safety regulations, Hawaii can simultaneously and more effectively control invasive species that cause negative human-wildlife interactions and ecological damage and provide residents with a sustainable supply of locally sourced protein and other organic products.

Author Contributions: E.C.R. contributed to the conceptualization, data collection and analysis, and drafting of the manuscript. C.K.W. contributed to the conceptualization, funding/resources, and revising of the manuscript. All authors have read and agreed to the published version of the manuscript.

Funding: The APC was funded by the University of Arkansas System Division of Agriculture. 
Institutional Review Board Statement: The study was conducted in accordance with the Declaration of Helsinki, and approved by the Institutional Review Board of the University of Delaware (\#544885-1, 23 September 2013).

Informed Consent Statement: Informed consent was obtained from all subjects involved in the study.

Data Availability Statement: The data presented in this study are available on request from the corresponding author. The data are not publicly available due to participant confidentiality.

Acknowledgments: We thank all of the individuals and business representatives who participated in this survey for their time and effort.

Conflicts of Interest: The authors declare no conflict of interest.

\section{References}

1. Mysterud, A.; Strand, O.; Rolandsen, C.M. Efficacy of recreational hunters and marksmen for host culling to combat chronic wasting disease in reindeer. Wildl. Soc. Bull. 2019, 43, 683-692. [CrossRef]

2. Blossey, B.; Curtis, P.; Boulanger, J.; Dávalos, A. Red oak seedlings as indicators of deer browse pressure: Gauging the outcome of different white-tailed deer management approaches. Ecol. Evol. 2019, 9, 13085-13103. [CrossRef] [PubMed]

3. Pasko, S.; Goldberg, J. Review of harvest incentives to control invasive species. Manag. Biol. Invasions 2014, 5, 263. [CrossRef]

4. Weeks, P.; Packard, J. Feral hogs: Invasive species or nature's bounty? Hum. Organ. 2009, 68, 280-292. [CrossRef]

5. Nugent, G.; Choquenot, D. Comparing cost-effectiveness of commercial harvesting, state-funded culling, and recreational deer hunting in New Zealand. Wildl. Soc. Bull. 2004, 32, 481-492. [CrossRef]

6. Vercauteren, K.C.; Anderson, C.W.; Van Deelen, T.R.; Drake, D.; Walter, W.D.; Vantassel, S.M.; Hygnstrom, S.E. Regulated commercial harvest to manage overabundant white-tailed deer: An idea to consider? Wildl. Soc. Bull. 2011, 35, 185-194. [CrossRef]

7. Mawson, P.R.; Hampton, J.O.; Dooley, B. Subsidized commercial harvesting for cost-effective wildlife management in urban areas: A case study with kangaroo sharpshooting. Wildl. Soc. Bull. 2016, 40, 251-260. [CrossRef]

8. Parks, J.P. Does commercial harvesting of introduced wild mammals contribute to their management as conservation pests. In Biological Invasions in New Zealand; Allen, R.B., Lee, W.G., Eds.; Springer: Berlin/Heidelberg, Germany, 2006 ; pp. 407-420.

9. Hess, S.C.; Judge, S.W. Modeling scenarios for the management of axis deer in Hawai'i. Pac. Sci. 2021, 75, 561-573. [CrossRef]

10. Duffy, D.J.; Lepczyk, C.A. The historical ecology of game species introductions in Hawai'i. Pac. Sci. 2021, 5, 1-41.

11. Nosowitz, D. The Struggle to Contain, and Eat, the Invasive Deer Taking over Hawai. Modern Farmer. 24 May 2021. Available online: https:/ / modernfarmer.com/2021/05/the-struggle-to-contain-and-eat-the-invasive-deer-taking-over-hawaii/ (accessed on 14 January 2022).

12. Lohr, C.A.; Lepczyk, C.A.; Johnson, E.D. The islands are different: Human perceptions of game species in Hawaii. Environ. Manag. 2014, 54, 814-827. [CrossRef] [PubMed]

13. Flaherty, K.L.; Turk, P.J.; Anderson, J.T. Comparing stakeholder attitudes toward white-tailed deer and rare plant management in Canaan Valley, West Virginia. Glob. Ecol. Conserv. 2019, 17, e00519. [CrossRef]

14. Thresher, R.E.; Jones, M.; Drake, D.A.R. Stakeholder attitudes towards the use of recombinant technology to manage the impact of an invasive species: Sea lamprey in the North American Great Lakes. Biol. Invasions 2019, 21, 575-586. [CrossRef]

15. Bryman, A. Social Research Methods, 4th ed.; Oxford University Press: Oxford, UK, 2012.

16. Dillman, D.A.; Smyth, J.D.; Christian, L.M. Internet, Phone, Mail, and Mixed-Mode Surveys: The Tailored Design Method; John Wiley \& Sons: Hoboken, NJ, USA, 2014.

17. Howard, B.S.; Goehl, S.A.; Jenkins, M.A.; Miller, D.R.; Brinkman, J.L. Use of vegetation monitoring and professional sharpshooting in white-tailed deer (Odocoileus virginianus) management at Eagle Creek Park in Indianapolis. Cities Environ. 2020, $13,16$.

18. Urbanek, R.E.; Nielsen, C.K.; Davenport, M.A.; Woodson, B.D. Perceived and desired outcomes of suburban deer management methods. J. Wildl. Manag. 2015, 79, 647-661. [CrossRef]

19. Wallace, L.N. College Student Involvement in Hunting and Shooting Sports: What Drives Participation? Rec. Sports J. 2020, 44, 126-138. [CrossRef]

20. Peterson, M.N.; Nelson, M.P. Why the North American model of wildlife conservation is problematic for modern wildlife management. Hum. Dimens. Wildl. 2017, 22, 43-54. [CrossRef]

21. Phillips, L. Bringing More South African Game Meat to Dinner Tables. Farmer's Weekly. 30 November 2019. Available online: https:/ / www.farmersweekly.co.za/animals/game-and-wildlife/bringing-more-south-african-game-meat-to-dinnertables / (accessed on 14 January 2022). 